\title{
A Case of Anomalous Left Anterior Descending Artery Originating From the Right Sinus of Valsalva
}

\author{
Niravkumar Patel ${ }^{1}$, Sukhdeep Bhogal ${ }^{2}$, Vijay Ramu ${ }^{2}$, Thomas Helton ${ }^{3}$ \\ 1. Internal Medicine, Johnston Memorial Hospital, Abingdon, USA 2. Division of Cardiology, Department of Internal \\ Medicine, East Tennessee State University, Johnson City, USA 3. Division of Cardiology, James H. Quillen Veterans \\ Affairs Medical Center, James H. Quillen College of Medicine, Johnson City, USA
}

Corresponding author: Niravkumar Patel, patelniravmd@gmail.com

\begin{abstract}
The anomalous origin of coronary arteries has been extensively documented in the literature. Most of the anomalies are incidentally found either during coronary angiography or imaging studies and are usually benign; however, malignant outcomes have been reported in the literature. Here, we present the case of a 76-year-old male with non-ST segment elevation myocardial infarction who was found to have an asymptomatic anomalous origin left anterior descending artery from the right sinus of Valsalva.
\end{abstract}

Review began 05/27/2021 Review ended 05/31/2021 Published 06/10/2021

\section{() Copyright 2021}

Patel et al. This is an open access article distributed under the terms of the Creative Commons Attribution License CC-BY 4.0., which permits unrestricted use, distribution, and reproduction in any medium, provided the original author and source are credited.
Categories: Cardiac/Thoracic/Vascular Surgery, Cardiology, Anatomy

Keywords: coronary artery, left anterior descending artery (lad), right coronary artery (rca), anomalous coronary artery, non-st segment elevation myocardial infarction (nstemi), right sinus of valsalva

\section{Introduction}

The anomalous origin of coronary arteries has been extensively documented in the literature; however, the isolated coronary artery anomaly (CAA) is rare (0.6\%-1.2\%) [1-3]. Even rarer is the isolated anomalous origin of the left anterior descending artery (LAD) from the right sinus of Valsalva (RSV). Most of the anomalies are incidentally found during coronary angiography, coronary computed tomographic angiography, or coronary magnetic resonance angiography of coronary vessels. About $80 \%$ of the anomalies are benign and are asymptomatic; however, malignant outcomes have also been documented [4]. Here, we present the case of a 76-year-old male with non-ST segment elevation myocardial infarction (NSTEMI) who was found to have an asymptomatic anomalous origin of LAD from the RSV. To the best of our knowledge, only 67 such cases have been reported in the literature since the 1960s.

\section{Case Presentation}

A 76-year-old male presented to our hospital complaining of dyspnea on exertion and substernal chest pain radiating to the left arm that was relieved by nitroglycerine and rest. He had documented coronary artery disease with percutaneous coronary intervention (PCI) to the right coronary artery (RCA) and ramus intermedius (RI) done more than five years prior to presentation. Other medical history consisted of hypertension, dyslipidemia, chronic obstructive pulmonary disease, obstructive sleep apnea, and hepatitis C. He had a 40 pack-year smoking history but no illicit drug use history. Family history was negative for heart disease.

Physical exam showed an obese male with normal vital signs. He had a regular heart rate and rhythm without any murmur or jugular venous distension. Lungs were clear to auscultation and no evidence of peripheral edema or pulse deficit was noted in the extremities. The rest of the physical examination was largely unremarkable.

Electrocardiogram (EKG) showed normal sinus rhythm with new T-wave inversions in anterolateral leads (Figure 1). Troponin I peaked at $40.2 \mathrm{ng} / \mathrm{ml}$. He was given aspirin $325 \mathrm{mg}$ and was started on a heparin drip. Bedside echocardiogram showed an ejection fraction of $40 \%-45 \%$ and moderate apical hypokinesis. A left heart catheterization was performed urgently showing in-stent thrombosis of a prior RI stent and an accidental finding of anomalous LAD originating from RSV instead of the left coronary cusp (Figures 2, 3). The patient subsequently underwent PCI of RI with a 2.5 x $38 \mathrm{~mm}$ drug-eluting stent (Figure 4). Nonobstructive disease was noted in other vessels. His postoperative course was uneventful and he was discharged on appropriate guideline-directed medical therapy. 


\section{Cureus}

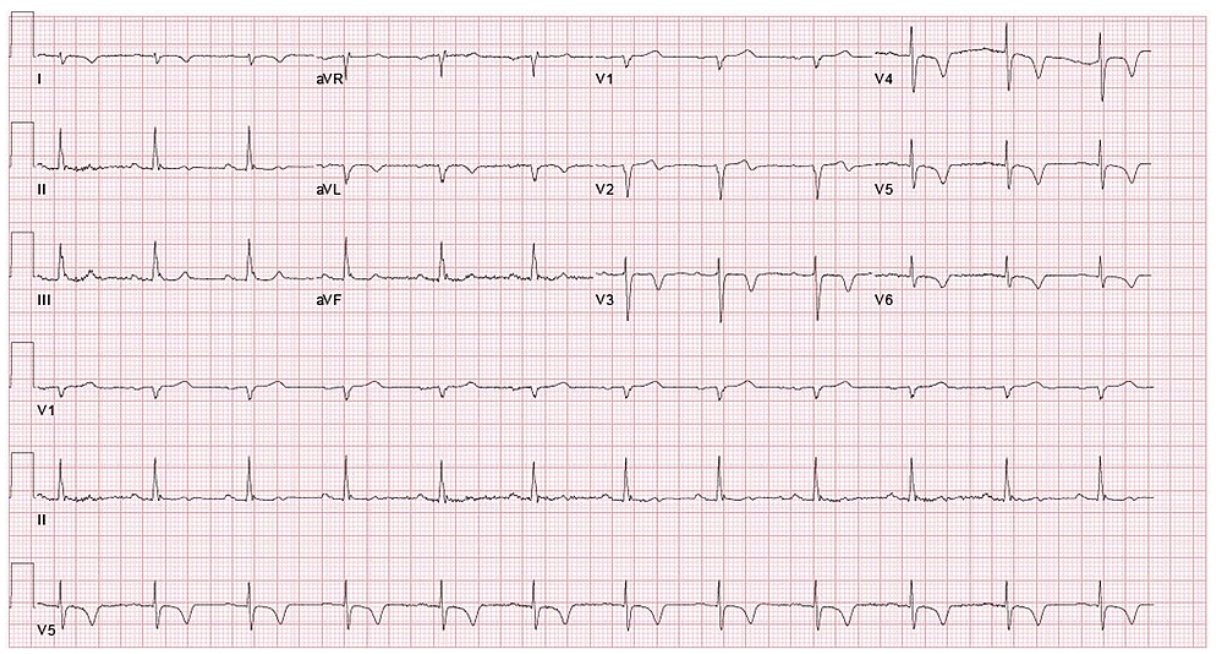

FIGURE 1: EKG showing sinus rhythm and anterolateral T-wave inversions

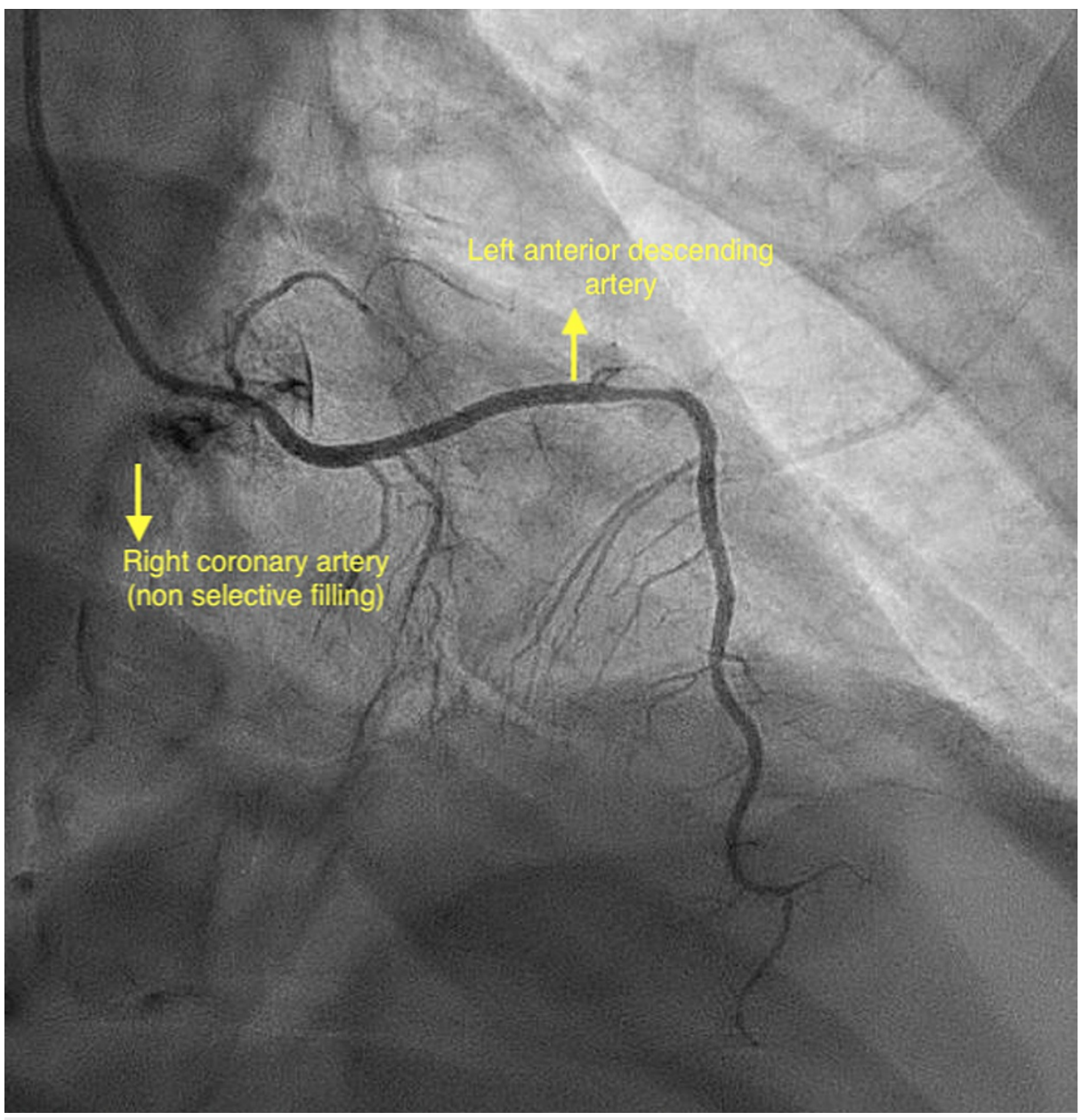

FIGURE 2: Right anterior oblique cranial view showing the left anterior descending artery arising from the right sinus of Valsalva with selective catheter engagement coursing left and upward before turning toward the apex 


\section{Cureus}

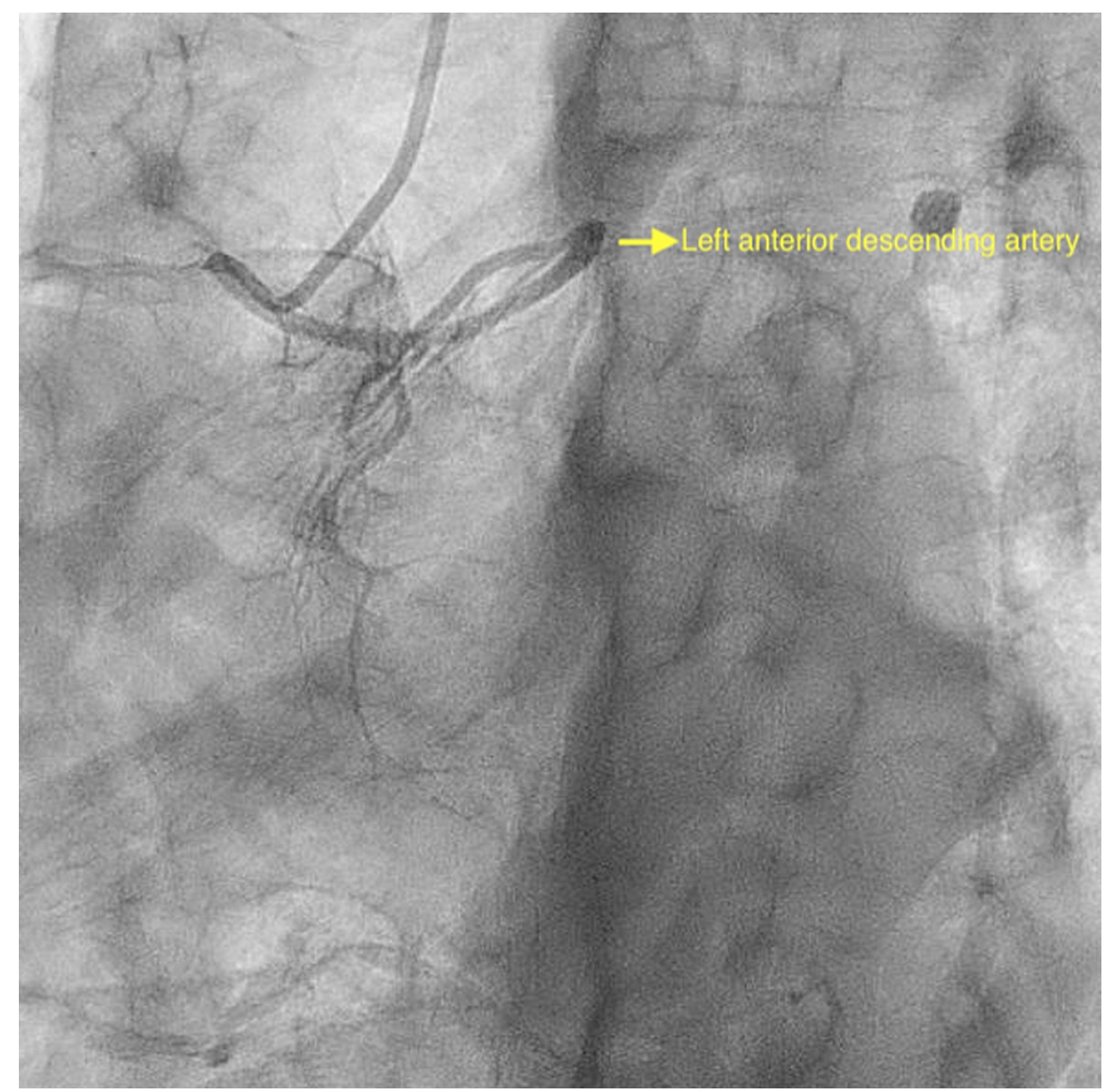

FIGURE 3: Left anterior oblique caudal view showing the anomalous origin of the left anterior descending artery from the right sinus of Valsalva with selective catheter engagement 


\section{Cureus}

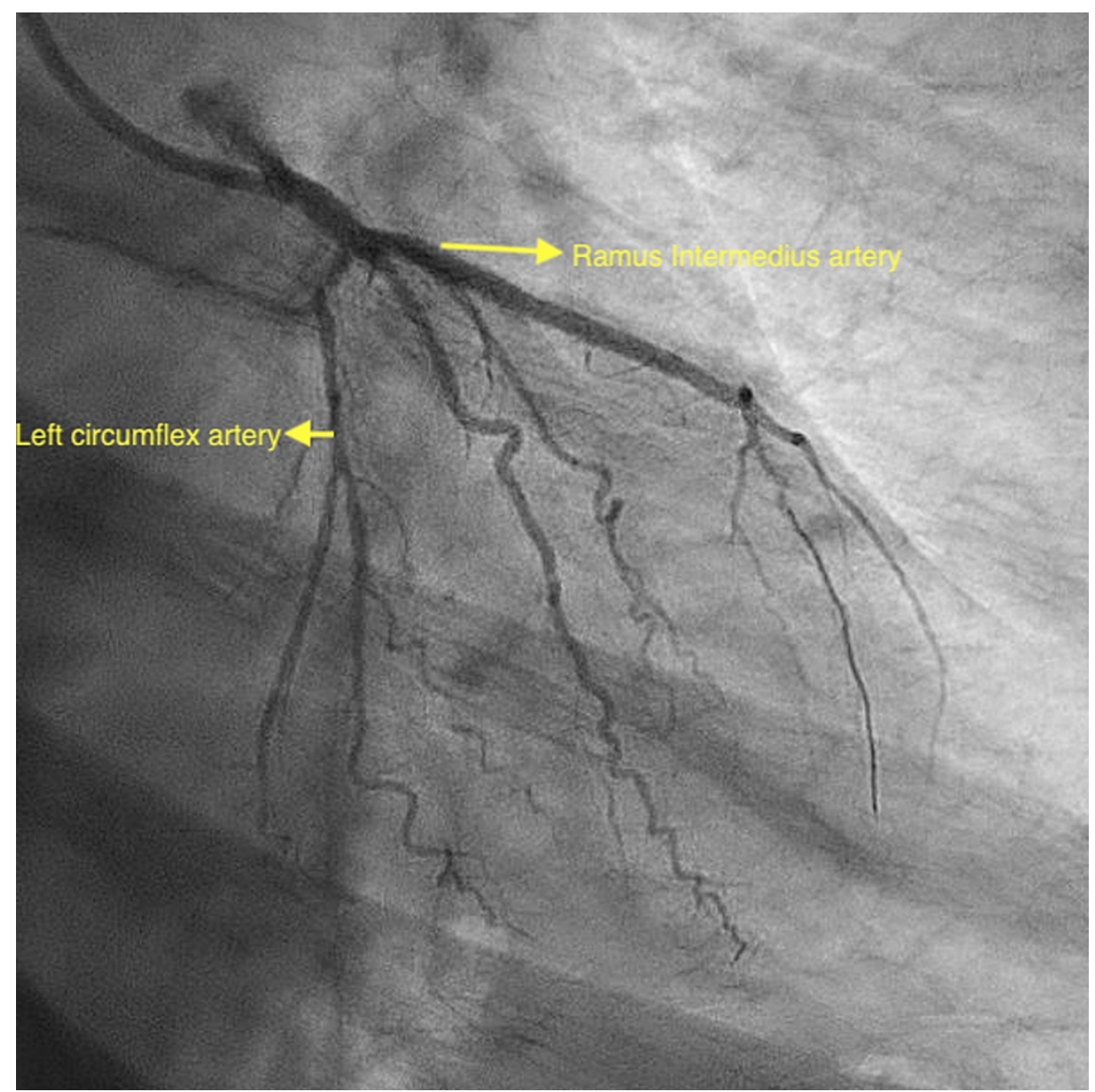

\section{FIGURE 4: Right anterior oblique caudal view showing the missing left anterior descending artery and ramus intermedius post-percutaneous coronary intervention}

\section{Discussion}

CAAs are rare and the prevalence ranges from $0.21 \%$ to $5.79 \%$ [1-3,5]. The anomalies may differ depending upon their origin, course, and termination. They can be associated with other congenital cardiac anomalies such as tetralogy of Fallot, bicuspid aortic valve, transposition of great vessels, and arteriovenous fistulae $[1,3,5]$. Isolated anomalous LAD originating from RSV is an extremely rare coronary anomaly. Yamanaka and Hobbs in a review of 126,595 angiographic cases found 38 patients with this anomaly with an incidence of $0.03 \%$, accounting for $2.3 \%$ of total coronary anomalies [3]. However, they did not discuss the clinical and angiographic features of these patients [6]. Two different retrospective reviews found 4 and 7 cases after reviewing 58,023 and 70,850 angiographies, respectively [6,7]. It typically takes an anterior free wall or a septal course, although retro-aortic and inter-arterial courses have been described in the literature $[8,9]$. Our patient had a benign anterior free wall course, in which LAD was seen passing to the left and upward before turning toward the apex in the right anterior oblique view (Figure 2) [9].

To the best of our knowledge, only 67 cases have been reported in the literature so far (Table 1 ). This anomaly should be differentiated from another anomaly in which LAD arises from the RCA, called as Type IV "dual LAD" anomaly, whose incidence is $0.01 \%-0.03 \%$ [10]. The majority of the CAAs are detected incidentally, and their clinical significance remains controversial. However, it has been postulated that an aberrant origin and the anomalous course could make them more prone to atherosclerosis [10]. Although CAAs are usually asymptomatic, they may present with angina, dyspnea, palpitations, syncope, cardiac arrest, and sudden cardiac death (SCD). According to Taylor et al., high-risk anatomy includes the course of the anomalous coronary artery between the aorta and pulmonary artery, and younger patients have a higher risk of SCD especially with exertional activities than the elderly [11]. CAAs are also the second most leading cause of SCD in athletes at 19\% as compared to hypertrophic cardiomyopathy at 36\% [12]. Other anatomic characteristics of CAAs predisposing them to grave outcomes include single coronary artery, origin from the pulmonary artery or opposite aortic sinus, intramural course, acute angle takeoff and ostial stenosis or atresia $[2-4,6,10]$. Asymptomatic CAAs rarely need interventions; however, symptomatic individuals with a malignant course often require surgical correction [8]. PCI of atherosclerotic lesion in anamalous coronary 


\section{Cureus}

vessels could be challenging and is often limited by individual expertise [6].

\begin{tabular}{|c|c|c|c|}
\hline & Author & Number of cases & Number of total cases evaluated \\
\hline 1 & Rajani et al. [13] & 1 & 1 \\
\hline 2 & Contractor et al. [14] & 1 & 1 \\
\hline 3 & Luebbering et al. [15] & 1 & 1 \\
\hline 4 & Straalen et al. [16] & 2 & 2 \\
\hline 5 & Fiorella et al. [17] & 1 & 5 \\
\hline 6 & Tacar et al. [18] & 1 & 1 \\
\hline 7 & Takenaka et al. [19] & 1 & 1 \\
\hline 8 & Antonellis et al. [20] & 1 & 1 \\
\hline 10 & Vicelj et al. [21] & 1 & 1 \\
\hline 11 & Dalal et al. [22] & 1 & 1 \\
\hline 12 & Yamanaka et al. [3] & 38 & 126,595 \\
\hline 13 & Coyle and Thomas [8] & 1 & 1 \\
\hline 14 & Harikrishnan et al. [23] & 1 & 7400 \\
\hline 15 & Barriales et al. [24] & 2 & 13,500 \\
\hline 16 & Sirasapalli et al. [25] & 1 & 8021 \\
\hline 17 & Ghadri et al. [26] & 2 & 11,541 \\
\hline 18 & Göl et al. [7] & 4 & 58,023 \\
\hline 19 & Tuncer et al. [6] & 7 & 70,850 \\
\hline
\end{tabular}

TABLE 1: Summary of data on anomalous left anterior descending artery originating from the right coronary sinus

Our patient had an anomalous origin of LAD from RSV; however, considering his age and no history of syncope and malignant arrhythmias, the course was likely benign and hence we opted to avoid any unnecessary imaging or intervention. He is currently on maximal medical therapy and has remained asymptomatic since the correction of the culprit lesion.

\section{Conclusions}

CAAs are rare and usually asymptomatic; however, a high index of suspicion is required on part of clinicians about malignant characteristics that have the potential for lethal outcomes. Only a few cases of LAD from RSV have been documented in the literature. Our case highlights a benign course, but high-risk features should always be kept in mind.

\section{Additional Information \\ Disclosures}

Human subjects: All authors have confirmed that this study did not involve human participants or tissue. Conflicts of interest: In compliance with the ICMJE uniform disclosure form, all authors declare the following: Payment/services info: All authors have declared that no financial support was received from any organization for the submitted work. Financial relationships: All authors have declared that they have no financial relationships at present or within the previous three years with any organizations that might have an interest in the submitted work. Other relationships: All authors have declared that there are no other relationships or activities that could appear to have influenced the submitted work.

\section{References}

1. Pérez-Pomares JM, de la Pompa JL, Franco D, et al.: Congenital coronary artery anomalies: a bridge from 
embryology to anatomy and pathophysiology-a position statement of the development, anatomy, and pathology ESC Working Group. Cardiovasc Res. 2016, 109:204-216. 10.1093/cvr/cvv251

2. Ono M, Brown DA, Wolf RK: Two cases of anomalous origin of LAD from right coronary artery requiring coronary artery bypass. Cardiovasc Surg. 2003, 11:90-92. 10.1016/s0967-2109(02)00149-7

3. Yamanaka O, Hobbs RE: Coronary artery anomalies in 126,595 patients undergoing coronary arteriography. Cathet Cardiovasc Diagn. 1990, 21:28-40. 10.1002/ccd.1810210110

4. Anantha Narayanan M, DeZorzi C, Akinapelli A, Mahfood Haddad T, Smer A, Baskaran J, Biddle WP: Malignant course of anomalous left coronary artery causing sudden cardiac arrest: a case report and review of the literature. Case Rep Cardiol. 2015, 2015:806291. 10.1155/2015/806291

5. Akcay M, Camlıdag I, Gulel O: Percutaneous coronary intervention for coronary arteries with origin and course anomalies: case reports and literature review. J Tehran Heart Cent. 2019, 14:141-145.

6. Tuncer C, Batyraliev T, Yilmaz R, Gokce M, Eryonucu B, Koroglu S: Origin and distribution anomalies of the left anterior descending artery in 70,850 adult patients: multicenter data collection. Catheter Cardiovasc Interv. 2006, 68:574-585. 10.1002/ccd.20858

7. Göl MK, Ozatik MA, Kunt A, et al.: Coronary artery anomalies in adult patients. Med Sci Monit. 2002, 8:636641.

8. Coyle L, Thomas WJ: Anomalous left anterior descending coronary artery: malignant hospital course of a not so benign anomaly. Catheter Cardiovasc Interv. 2000, 51:468-470. 10.1002/1522726X(200012)51:4<468::AID-CCD20>3.0.CO;2-S

9. Sorajja P, Lim M, Kern M: Kern's Cardiac Catheterization Handbook. Elsevier, Philadelphia, PA; 2019.

10. Mironov A, Galligan S, Kakauridze A, Marmur JD: An obstructed anomalous left anterior descending coronary artery arising from the right coronary artery requiring surgical intervention. Case Rep Cardiol. 2016, 2016:3589214. 10.1155/2016/3589214

11. Taylor AJ, Rogan KM, Virmani R: Sudden cardiac death associated with isolated congenital coronary artery anomalies. J Am Coll Cardiol. 1992, 20:640-647. 10.1016/0735-1097(92)90019-j

12. Maron BJ, Thompson PD, Puffer JC, et al.: Cardiovascular preparticipation screening of competitive athletes. A statement for health professionals from the Sudden Death Committee (clinical cardiology) and Congenital Cardiac Defects Committee (cardiovascular disease in the young), American Heart Association. Circulation. 1996, 94:850-856. 10.1161/01.cir.94.4.850

13. Rajani AR, Rafiq MA, Mian MH, Baslaib FO: Anomalous left anterior descending artery: an uncommon cause of ST elevation myocardial infarction. BMJ Case Rep. 2015, 2015:bcr2014209221. 10.1136/bcr-2014-209221

14. Contractor T, Mannem SR, Ameda S, Punnam SR: Isolated anomalous left anterior descending artery arising from right sinus of Valsalva: a rare anomaly. Acta Cardiol. 2010, 65:489-490. 10.2143/AC.65.4.2053914

15. Luebbering ZT, Abdullah O, Mansour AM, Bhardwaj B, Aggarwal K: ST-elevation myocardial infarction in a patient with anomalous left anterior descending artery and absent left circumflex. Cureus. 2018, 10:e3311. 10.7759/cureus.3311

16. van Straalen MJ, Gijs Mast E, Ernst SM: The value of computed tomography in combination with a percutaneous transluminal coronary angioplasty guide wire for identifying the definite course of an anomalous left anterior descending artery. Int J Cardiol. 1996, 53:189-192. 10.1016/0167-5273(95)02522-7

17. Fiorella A, Basso P, Lanzone S, et al.: Anomalous origin of the coronary arteries: five case reports and review of the literature. (Article in Italian). G Ital Cardiol (Rome). 2010, 11:778-782.

18. Tacar O, Karadede A: Anomaly of the left anterior descending coronary artery arising from the right sinus of valsalva and ventricular septal defect in adult: a rare case. Yonsei Med J. 2005, 46:729-732. 10.3349/ymj.2005.46.5.729

19. Takenaka T, Horimoto M, Fujiwara M: Anomalous origin of the left anterior descending coronary artery from the right sinus of Valsalva associated with effort angina pectoris. Eur Heart J. 1993, 14:129-131. 10.1093/eurhearti/14.1.129

20. Antonellis J, Kostopoulos K, Margaris N, et al.: Angioplasty of a left anterior descending artery originating from the right sinus of Valsalva (discussion in decision making). Int J Cardiol. 1996, 56:86-89. 10.1016/01675273(96)02730-1

21. Vincelj J, Todorović N, Marusić P, Puksić S: Anomalous origin of the left coronary artery from the right sinus of Valsalva in a 62-year-old woman with unstable angina pectoris: a case report. Int J Cardiol. 2010, 142:E35-E37. 10.1016/j.ijcard.2008.11.182

22. Dalal JJ, West RO, Parker JO: Isolated anomaly of the left anterior descending coronary artery . Cathet Cardiovasc Diagn. 1984, 10:189-193. 10.1002/ccd.1810100212

23. Harikrishnan S, Jacob SP, Tharakan J, et al.: Congenital coronary anomalies of origin and distribution in adults: a coronary arteriographic study. Indian Heart J. 2002, 54:271-275.

24. Barriales Villa R, Morís C, López Muñiz A, et al.: Adult congenital anomalies of the coronary arteries described over 31 years of angiographic studies in the Asturias Principality: main angiographic and clinical characteristics. (Article in Spanish). Rev Esp Cardiol. 2001, 54:269-281. 10.1016/s0300-8932(01)76308-7

25. Sirasapalli CN, Christopher J, Ravilla V: Prevalence and spectrum of coronary artery anomalies in 8021 patients: a single center study in South India. Indian Heart J. 2018, 70:852-856. 10.1016/j.ihj.2018.01.035

26. Ghadri JR, Kazakauskaite E, Braunschweig S, et al.: Congenital coronary anomalies detected by coronary computed tomography compared to invasive coronary angiography. BMC Cardiovasc Disord. 2014, 14:81. 10.1186/1471-2261-14-81 